\title{
PERENCANAAN BISNIS ERPIN.BIZ SEBAGAI APLIKASI ERP FINANCIAL BERBASIS CLOUD COMPUTING UNTUK USAHA MIKRO, KECIL DAN MENENGAH
}

\author{
Seprihadi Natanael \\ Program Sistem Informasi, Program Studi Sistem Informasi, Universitas Bina Nusantara \\ Jln. K.H. Syahdan No. 9, Palmerah, Jakarta Barat, 11480 \\ Telp. (021) 5345830 \\ E-mail: seprihadi@binus.edu
}

\begin{abstract}
ABSTRAKSI
Tujuan dari penelitian ini adalah untuk menganalisa peluang dan kelayakan bisnis solusi ERP Financial berbasis cloud computing untuk Usaha Mikro, Kecil, dan Menengah di Indonesia. Perencanaan bisnis ini disusun berdasarkan hasil dari pembuatan analisa SWOT, strategi pemasaran, model bisnis, dan melakukan penilaian bisnis. Dapat disimpulkan bahwa bisnis ini layak dijalankan dilihat dari Return onInvestment (ROI) sebesar 438,43\% setelah jangka waktu 2,5 tahun.
\end{abstract}

Kata Kunci: Perencanaan Bisnis, ERP Financial, Cloud Computing, Usaha Mikro Kecil dan Menengah (UMKM) 


\section{PENDAHULUAN}

Usaha Mikro Kecil dan Menengah (UMKM) merupakan komponen vital bagi perekonomian Indonesia. Pada saat perekonomian dunia sedang terkena imbas krisis finansial, Indonesia bertahan karena didukung geliat usaha mikro kecil menengah yang bangkit memutar roda perekonomian. Berdasarkan data dari Kementrian Koperasi dan Usaha Kecil dan Menengah pada tahun 2012 terdapat 56.534.592 unit Usaha Mikro, Kecil dan Menengah di Indonesia. Jumlah ini meningkat sekitar 2,41\% atau 1.328.148 unit jika dibandingkan dengan jumlah tahun 2011 dan sekitar 4,98\% atau 2.710 .860 unit jika dibandingkan dengan jumlah tahun 2010 dengan pertumbuhan ratarata dari tahun 2009 sebesar 2,40\% per tahun. Apabila dibandingkan dengan jumlah penduduk, pertumbuhan jumlah UMKM di Indonesia naik dari 1,56\% pada tahun 2014, menjadi 3,1\% dari jumlah penduduk pada akhir tahun 2016.

Masalah manajemen keuangan dinilai menjadi kelemahan utama bagi pelaku UMKM dalam mengembangkan bisnisnya. Berdasarkan studi kasus terhadap UKM di Jawa Barat, jumlah usaha yang mempunyai laporan keuangan usaha terpisah dengan keuangan keluarga ditaksir hanya sekitar $30 \%$ dari total 8,2 juta UKM. Salah satu solusi TI yang dapat digunakan adalah pengunaan solusi Enterprise Resource Planning (ERP) Financial yang dapat mengintegrasikan proses bisnis perusahaan yang berkaitan dengan bidang Akuntansi dan Keuangan yang berbasis pada Cloud Computing.

Menurut riset yang dilakukan oleh Gartner pada Oktober 2012 mengenai alasan utama yang mendorong penggunaan SaaS pada tahun 2010-2012 adalah untuk mendapatkan jumlah total biaya perolehan yang lebih kecil dibandingkan dengan solusi on-premise dan diikuti dengan pertimbangan bahwa SaaS akan lebih mudah dan cepat untuk diimplementasikan dibandingkan dengan on-premise. Riset Gartner juga menyimpulkan bahwa penghasilan ERP berbasiskan SaaS diproyeksikan akan tumbuh sekitar $12 \%$ di seluruh dunia di tahun 2013 sampai dengan 17\% di tahun 2016. Menurut Gartner pertumbuhan cloud ERP juga terjadi di Asia Pasifik dimana untuk total penghasilan di tahun 2012 sebesar 934,1 juta USD yang meningkat dibandingkan penghasilan tahun 2011 sebesar 730,9 juta USD. Gartner juga menyebutkan bahwa Indonesia merupakan salah satu pasar yang sedang berkembang selain China, India, Malaysia, Thailand, Vietnam dan Filipina.
Cloud ERP di Indonesia juga sudah mulai diminati oleh perusahaan ERP dari luar negeri, karena pasar yang menjanjikan mengingat Cloud ERP di Indonesia masih terbilang baru. Untuk itu, maka perusahaan lokal juga harus mampu menghadirkan layanan Cloud ERP ini yang diharapkan dapat lebih sesuai dengan kebutuhan UKM di Indonesia, sebab untuk pasar ERP di Indonesia, seperti yang dikutip dari riset oleh Gartner, untuk pasar ERP di Asia Pasifik dibutuhkan penyedia layanan yang dapat dengan fleksibel menyesuaikan kebutuhan dan mengatasi permasalahan yang unik dimasing-masing negara.

Untuk itu pembuatan perencanaan bisnis Solusi ERP Financial berbasis cloud computing untuk Usaha Mikro, Kecil, dan Menengah (UMKM) ini dilakukan untuk menganalisa pasar SaaS ERP di Indonesia, dan menghadirkan bisnis ini untuk UMKM di Indonesia. Sebagai langkah awal solusi ini akan diperkenalkan dan dihadirkan untuk UMKM yang berada di Jabodetabek, dimana merupakan pusat industri dan perdagangan di Indonesia.

\section{METODE PENELITIAN}

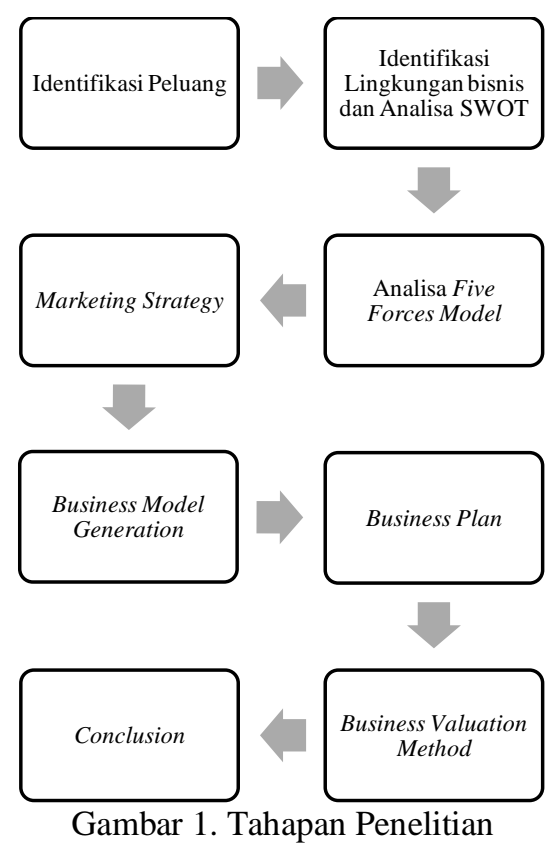

Perencanaan bisnis dimulai dengan terlebih dahulu melakukan identifikasi terhadap peluang dengan cara melihat perkembangan Usaha Mikro, Kecil, dan Menengah (UMKM) di Indonesia, khususnya di Jabodetabek, dan perkembangan solusi ERP berbasis cloud computing. Untuk memastikan adanya peluang tersebut, maka dilakukan identifikasi lingkungan bisnis dan analisa SWOT. Identifikasi lingkungan bisnis dilakukan terhadap lingkungan bisnis makro yaitu lingkungan ekonomi dan hukum, lingkungan teknologi, 
lingkungan persaingan, lingkungan sosial, dan lingkungan bisnis global.

Analisa SWOT juga dilakukan untuk dapat melihat kondisi lingkungan internal dan eksternal bisnis, untuk melihat kekuatan, kelemahan, peluang, dan ancaman untuk bisnis ini. Untuk lingkungan ekternal dapat dibandingkan dengan hasil identifikasi bisnis yang dilakukan sebelumnya. Selanjutnya dilakukan analisa Five Forces Model untuk mengetahui kondisi pasar yang sudah ada saat ini dan potensi perkembangan selanjutnya.

Dari hasil analisa tersebut maka akan digunakan sebagai acuan dalam membuat strategi pemasaran yang menggunakan teknik Top-Down yang terbagi menjadi tahapan segmentation, targeting, dan positioning. Alasan dipilihnya teknik ini karena bisnis masih baru dan hanya membutuhkan sumberdaya yang lebih sedikit, lebih fleksibel untuk diterapkan dan cocok untuk perusahaan yang sedang berkembang. Untuk mendukung kegiatan pemasaran digunakan bauran pemasaran yang terbagi dalam 7P's (product, price, place, promotion, people, process, dan physical evidence).

Untuk memudahkan pembuatan rencana bisnis, maka terlebih dahulu dibuat model bisnis menggunakan Business Model Canvas sebagai alat untuk menangkap, menganalisa, dan menciptakan integrasi di antara sembilan komponen model bisnis yang ada. Setelah mengetahui bisnis model, maka dibuatlah perencanaan bisnis untuk mendokumentasikan segala kebutuhan dan strategi yang diperlukan untuk menjalankan bisnis. Business plan akan dipergunakan oleh investor untuk menilai kelayakan bisnis dan acuan apakah investor akan menanamkan modalnya pada bisnis yang dibuat ini. Perencanaan bisnis akan berisi informasi mengenai bisnis pada umumnya, rencana keuangan, rencana operasional, rencana pengembangan, tim, dan penawaran kepada investor.

Setelah perencanaan bisnis dibuat maka akan dilakukan perhitungan atas nilai bisnis tersebut dengan metode Weighted Average Cost of Capital (WACC) dan BuildUp method. Walaupun pada dasarnya bisnis ini masih dalam tahap perencanan dan semua laporan keuangan masih dalam nilai estimasi, tetapi business valuation tetap perlu dilakukan dari sisi keuangannya untuk dapat melihat apakah investasi dalam bisnis ini akan menguntungkan bagi investor. Pada tahap akhir akan diambil kesimpulan mengenai kemungkinan bisnis ini untuk diterapkan di Indonesia.

\section{HASIL DAN DISKUSI}

\section{Executive Summary}

Perkembangan teknologi Cloud Computing dan model penyampaian perangkat lunak yang dikenal dengan Software-as-a-Service (SaaS) atau perangkat lunak sebagai layanan membantu UMKM agar dapat mengakses layanan perangkat lunak melalui koneksi internet dengan biaya bulanan yang kecil, dengan demikian mampu menyediakan akses dengan biaya yang efektif untuk pasar bisnis UMKM. Salah satu solusi yang ditawarkan melalui model ini adalah ERP Financial yang bertujuan untuk mengintegrasikan proses bisnis perusahaan yang berkaitan dengan bidang akuntansi dan keuangan.

ERPin.Biz hadir sebagai platform yang menyediakan solusi ERP Financial berbasis cloud computing untuk UMKM di Indonesia, khususnya Jabodetabek. ERPin.Biz dapat diakses melalui web browser dimanapun, kapanpun, dan menggunakan perangkat apapun, sehingga dapat membantu pengelola bisnis dalam mendapatkan informasi yang real-time dan terintegrasi tanpa membutuhkan investasi di bidang IT yang besar. Berdasarkan rencana keuangan yang sudah disusun dapat disimpulkan bahwa bisnis ini layak dijalankan dilihat dari Return on-Investment (ROI) sebesar 438,43\% setelah jangka waktu 2,5 tahun.

\section{Analisa Five Forces Model}

Salah satu pertimbangan untuk pengembangan sebuah bisnis baru adalah mengenai lingkungan persaingan yang dapat diketahui dengan analisa Five Forces Model. Adapun hasil analisa Five Forces Model terhadap ERPin.Biz adalah sebagai berikut:

1. Persaingan Antar Kompetitor

Berdasarkan segmentasi pasar dari masing-masing pesaing maka kategori persaingan dalam bisnis ini adalah menengah karena pesaing yang memiliki segmentasi pasar yang sama hanya Openbravo dan OpenERP.

2. Ancaman Datangnya Pesaing Baru

Kemudahan pesaing baru untuk memasuki bisnis ini karena tidak memerlukan investasi yang tinggi, sehingga banyak pendatang baru yang juga dapat memasuki bisnis ini. Belum adanya peraturan pemerintah yang jelas mengenai penyediaan layanan di bidang cloud ERP, sehingga untuk pendatang baru dapat hadir dari perusahaan di dalam negeri maupun di luar negeri, sehingga persaingan juga semakin ketat.

3. Ancaman Produk Pengganti

Pemilihan produk pengganti yang digunakan oleh UMKM sebagian besar dilakukan berdasarkan biaya yang dikeluarkan, kemudahan dalam penggunaan dan pengelolaan produk, pengetahuan pengelola UMKM atas produk yang ada di pasar, dan manfaat yang diperoleh dari produk pengganti tersebut.

4. Daya Tawar Pembeli

Daya tawar pembeli pada mulanya akan tinggi karena banyaknya produk pengganti dan juga pesaing yang menyediakan layanan sejenis sehingga pembeli dapat dengan mudah memilih produk yang lain. 
5. Daya Tawar Pemasok

Daya tawar dari pemasok dalam hal ini adalah perusahaan penyedia hosting dan perusahaan penyedia peralatan komputer adalah rendah karena banyaknya perusahaan penyedia hosting dan perangkat komputer dengan harga yang relatif sama.

3. Marketing Strategy

Strategi pemasaran dilakukan untuk memastikan produk dapat dikenal, diinginkan, dan digunakan oleh pelanggan. Karena bisnis ini masih baru, maka teknik pemasaran yang akan dilakukan adalah menggunakan teknik Top-Down yang terbagi menjadi tahapan segmentation, targeting, dan positioning. Teknik ini sesuai untuk diterapkan karena hanya membutuhkan sumber daya yang lebih sedikit, lebih fleksibel untuk diterapkan dan cocok untuk perusahaan yang sedang berkembang. Untuk mendukung kegiatan pemasaran digunakan bauran pemasaran yang terbagi dalam 7P's (product, price, place, promotion, people, process, dan physical evidence).

Jenis segmentasi yang dipilih adalah Segmented Market, dimana pelanggan dibedakan berdasarkan kebutuhan dan masalah yang berbeda. Hal ini dilakukan agar produk yang dibuat dapat benar-benar sesuai dengan kebutuhan dan mengatasi masalah pasar yang dipilih.

Segmentasi yang dibuat untuk bisnis ini adalah sebagai berikut:

1. Kategori usaha, yaitu apakah termasuk kategori Usaha Besar, Menengah, atau UMKM.

2. Bidang usaha, yaitu apakah usaha tersebut bergerak di bidang perdagangan, jasa, atau manufaktur.

3. Aplikasi yang digunakan untuk untuk pembuatan laporan keuangan, yaitu apakah usaha tersebut sudah menggunakan aplikasi untuk membuat laporan keuangannya

Target pasar dari bisnis berdasarkan segmentasi yang sudah dilakukan adalah sebagai berikut:

1. Kategori usaha, yaitu kategori UMKM berdasarkan kriteria yang ada pada Undang-Undang Nomor 20 Tahun 2008 tentang Usaha Mikro, Kecil, dan Menengah.

2. Bidang usaha, yaitu usaha yang bergerak di bidang perdagangan dan jasa.

3. Aplikasi yang digunakan untuk untuk pembuatan laporan keuangan, yaitu usaha tersebut masih belum menggunakan aplikasi untuk membuat laporan keuangannya atau masih melakukannya secara manual.

4. Pilihan metode penyampaian aplikasi, yaitu akan menggunakan metode on-cloud.

5. Lokasi usaha, yaitu untuk yang lokasi usahanya berada di Jabodetabek.

Differensiasi yang akan dilakukan adalah dengan membuat produk yang sesuai dengan peraturan perpajakan Indonesia dan dibuat dengan teknik cocreation, dimana akan melibatkan pemilik UMKM, konsultan perpajakan, pemerintah, dan developer dalam pembuatan dan pengembangan produk agar benar-benar bermanfaat untuk pelanggan.

Posisi yang ingin dicapai oleh perusahaan adalah untuk menjadi pilihan utama (top of choice) dikalangan UMKM, dan menjadi partner bagi UMKM dalam perkembangan dan kemajuan usahanya. Hal ini dicapai dengan cara memberikan produk yang berkualitas dengan harga yang terjangkau dan mudah digunakan, serta dapat diakses kapanpun, dimanapun, dan dengan menggunakan perangkat apapun.

\section{Business Model}

Pembuatan business model akan dilakukan dengan terlebih dahulu membuat business model canvas yang dipopulerkan oleh Alexander Osterwalder dan Yves Pigneur yang terdiri dari sembilan komponen yang saling terkait satu dengan yang lainnya. Pembuatan business model canvas dimulai dari penentuan segmentasi pelanggan, value proposition, kanal, hubungan dengan pelanggan yang mana keempat komponen ini akan menentukan cara perusahaan mendapatkan sumber pendapatan. Kemudian dilanjutkan dengan menentukan partnership kunci, aktivitas kunci, dan sumberdaya kunci yang mana ketiga komponen ini menentukan struktur biaya yang akan dikeluarkan oleh perusahaan. Berikut ini adalah business model canvas yang sudah dibuat untuk ERPin.Biz:

1. Jenis segmentasi pelanggan yang dipilih adalah Segmented Market, dimana pelanggan dibedakan berdasarkan kebutuhan dan masalah yang berbeda. Hal ini dilakukan agar produk yang dibuat dapat benar-benar sesuai dengan kebutuhan dan mengatasi masalah pasar yang dipilih.

2. Value proposition yang akan diberikan kepada pelanggan melalui produk yang ditawarkan adalah sesuatu yang baru (newness) dimana untuk layanan ERP Financial berbasis cloud computing ini mungkin belum dikenal oleh UMKM. Perusahaan juga menawarkan kenyamanan, kemudahan dan manfaat penggunaan (convenience/usability) untuk kemajuan usaha dan meningkatkan kemampuan bersaing. Nilai yang lain adalah accessibility, yaitu kemudahan dan variasi cara untuk mengakses layanan ini, kapan pun, dimana pun, dan dengan menggunakan device apa pun.

3. Kanal yang digunakan untuk bisnis ini adalah dengan own-direct yaitu menyediakan kanal distribusi sendiri melalui website dan penjualan yang dilakukan secara langsung dengan menghubungi dan mendatangi pelanggan. Selain itu juga dilakukan melalui partner secara indirect yaitu dengan cara membuat program affiliasi, dimana penjualan akan dilakukan oleh pelanggan kepada pelanggan yang lain melalui sistem yang sudah disediakan dan melalui aliansi strategis dengan asosiasi pengusaha dan pemerintah.

4. Hubungan dengan pelanggan dilakukan dengan cara menyediakan personal assistance yang dapat dihubungi secara langsung melalui live-chat, 
telepon, email, maupun bertemu langsung. Perusahaan juga akan melibatkan pelanggan secara langsung dalam pembuatan produk melalui cocreation, sehingga pelanggan merasa dihargai dan akan lebih senang menggunakan produk yang terdapat partisipasi dari pelanggan secara langsung. Perusahaan juga menyediakan layanan secara selfservice dan otomatis sehingga dapat memberikan kebebasan dan kemandirian kepada pelanggan. Setiap input dari pelanggan akan mendapatkan tanggapan sesegera mungkin, begitupun dengan informasi yang perlu disampaikan kepada pelanggan akan dilakukan secara periodik dan secara otomatis.

5. Sumber pendapatan utama dari bisnis adalah dari biaya berlangganan yang dibayarkan oleh pelanggan atas produk yang digunakan yaitu untuk kategori standar dan premium. Sedangkan untuk produk versi percobaan, sumber pendapatan didapatkan dari pendapatan iklan. Mekanisme harga yang digunakan adalah dengan Fixed Menu Pricing, dimana harga sudah ditentukan terlebih dahulu dan berdasarkan variable yang tetap dan bergantung kepada fitur produk.

6. Bisnis ini membutuhkan sumber daya untuk menjalankan operasional bisnis, yang terbagi menjadi tiga kelompok yaitu, sumber daya fisik, manusia, dan intelektual. Salah satu sumber daya utama dalam kelompok sumber daya fisik adalah infrastruktur teknologi informasi, seperti hosting, jaringan internet, dan pengamanan data. Sedangkan sumber daya manusia terdiri dari programmer, marketing, sales, customer service, technical support, dan lainnya. Sumber daya intelektual juga penting dan perlu untuk dikembangkan dan dikelola dengan baik seperti brand/merek dagang, hak cipta, dan pengetahuan yang dimiliki oleh organisasi. Keseluruhan sumber daya itu akan didapatkan dan dikelola oleh perusahaan dengan metode yang sesuai untuk setiap jenis sumber daya yang ada, karena untuk mendapatkan dan mengelolanya dibutuhkan biaya dan merupakan pengeluaran perusahaan.

7. Kegiatan yang dilakukan dalam bisnis ini adalah produksi walaupun tidak memproduksi barang, tetapi di dalamnya terdapat kegiatan yang berhubungan dengan desain, membuat, dan menyampaikan produk, dalam hal ini adalah layanan ERP berbasis cloud computing. Kegiatan lain adalah membangun platform. Dalam hal ini perusahaan membuat layanan ERP berbasis cloud computing sebagai platform layanan aplikasi ERP, dimana dapat dipergunakan oleh pelanggan, namun tidak dimiliki oleh pelanggan tersebut.

8. Partnership kunci yang dilakukan terhadap pemasok, asosiasi pengusaha, pemerintah, penyedia layanan internet, adalah melalui aliansi strategis.

9. Struktur biaya dibuat dengan didorong oleh nilai (value-driven). Bisnis ini akan memberikan value propositions sesuai dengan yang dibutuhkan oleh pelanggan, walaupun di balik itu akan ada biaya yang ditimbulkan. Meskipun strategi bisnis adalah dengan menggunakan strategi cost-leadership, namun value yang diberikan tetap harus menjadi fokus utama. Biaya yang terdapat dalam perusahaan dibagi menjadi dua yaitu, biaya tetap dan biaya variabel. Tujuan dari pembuatan struktur biaya ini adalah untuk mencapai economic of scale, dimana semakin banyak pelanggan yang menggunakan maka biaya yang ditimbulkan akan semakin kecil karena sudah dialokasikan kepada setiap pelanggan tersebut.

Berdasarkan business model canvas tersebut, maka ditetapkan model bisnis untuk ERPin.Biz yaitu menggunakan Unbundling Business Model. ERPin.Biz terdiri dari tiga kegiatan utama bisnis yaitu hubungan dengan pelanggan, inovasi produk, dan pengembangan infrastruktur.

\section{KESIMPULAN}

Berdasarkan hasil analisis masalah dari prosedur sistem berjalan dan perancangan sistem informasi akuntansi penggajian yang diusulkan, maka dapat disimpulkan bahwa:

1. Peluang dalam bisnis ERP Financial berbasis cloud computing untuk Usaha Mikro, Kecil, dan Menengah (UMKM) di Indonesia sangat besar, hal ini dibuktikan dengan hasil analisa terhadap lingkungan bisnis yang hasilnya adalah semakin berkembangnya pasar ERP berbasis cloud computing dan pertumbuhan ekonomi Indonesia yang stabil, mendorong semakin bertambahnya jumlah UMKM, khususnya yang berada di Jabodetabek. Pada saat ini, pesaing yang terdapat dalam pasar cloud ERP untuk UMKM masih sedikit, sedangkan jumlah potensi UMKM yang akan menggunakan cloud ERP masih terus bertumbuh.

2. Perencanaan Bisnis ERP Financial berbasis cloud computing untuk Usaha Mikro, Kecil, dan Menengah di Indonesia ini layak untuk dijalankan yang dapat dilihat dari beberapa kriteria keuangan yaitu dari Break-even-point (BEP) yang tercapai dalam waktu sekitar 15 (lima belas) bulan dan Return on-Investment (ROI) sebesar 438,43\% setelah jangka waktu 2,5 tahun yang dapat dilihat dari perencanaan keuangan yang sudah dilakukan. Menyusun perencanaan bisnis dan model bisnis untuk bisnis ERP Financial berbasis cloud computing untuk Usaha Mikro, Kecil, dan Menengah di Indonesia perlu mempertimbangkan inovasi produk, hubungan baik dengan pelanggan, dan pengembangan infrastruktur. Oleh karena itu model bisnis yang sesuai adalah dengan menggunakan Unbundling Business Model yang melakukan ketiga kegiatan tersebut secara terpisah, namun pada akhirnya memberikan dampak secara keseluruhan terhadap bisnis.

3. Perencanaan bisnis ini dapat diterima oleh investor, sehingga investor bersedia untuk menanamkan modalnya yang terbukti dari nilai 
Internal Rate of Return (IRR) sebesar 91\% setelah 2,5 tahun. Nilai ini jauh lebih besar dibandingkan dengan tingkat suku bunga deposito yang diperkirakan berkisar antara $8-15$ $\%$ per tahun.

\section{DAFTAR PUSTAKA}

Buecker, A., Lodewijkx, K., Moss, H., Skapinetz, K., \& Waidner, M. (2009). Cloud Security Guidance. IBM Recommendations for the Implementation of Cloud Security. IBM.

Bygrave, W., \& Zacharakis, A. (2011). Entrepreneurship. USA: John Wiley \& Sons, Inc.

Castellina, N. (2011). SaaS and Cloud ERP Trends, Observations, and Performance 2011. Aberdeen Group.

Dai, W. (2009). The Impact of Emerging Technologies on Small and Medium Enterprises (SMEs). Journal of Business Systems, Governance and Ethics, Vol 4 No 4, p:53-60.

Dorf, R. C., \& Byers, T. H. (2008). Technology Ventures From Idea to Enterprise. New York: McGraw-Hill.

Gelinas, U. J., Dull, R. B., \& Wheeler, P. (2012). Accounting Information Systems. Mason: SouthWestern College Publishing.

Hall, J. A. (2008). Accounting Information Systems. Mason: South-Western Cengage Learning.

Kompas. (2012, June 20). Indonesia Mampu Bertahan karena Didukung UKM. Retrieved from Kompas.com: http://bisniskeuangan.kompas.com/read/2012/06/2
0/18542369/Indonesia.Mampu.Bertahan.karena.Di dukung.UKM

Kotler, P., \& Armstrong, G. (2012). Principles of Marketing. New Jersey: Pearson Education, Inc.

Malhotra, R., \& Temponi, C. (2010). Critical Decisions for ERP Integration: Small Business Issues. International Journal of Information Management, 28-37.

Monk, E. F., \& Wagner, B. J. (2009). Concepts in Enterprise Resource Planning. Boston: Course Technology Cengage Learning.

Nickels, W. G., McHugh, J. M., \& McHugh, S. M. (2008). Understanding Business. New York: McGraw-Hill.

Obrien, J., \& Marakas, G. (2011). Management Information Systems. New York: McGrawHill/Irwin.

Osterwalder, A., \& Pigneur, Y. (2010). Business Model Generation: A Handbook for Visionaries, Game Changers, and Challengers. New Jersey: John Wiley \& Sons, Inc.

Porter, M. E. (1998). On Competition. Boston: Harvard Business School Pres.

Raihana, H. F. (2012). Cloud ERP - A Solution Model. International Journal of Computer Science and Information Technology \& Security, 79-79.

Saputro, J., Handayani, P. W., Hidayanto, A. N., \& Budi, I. (2010). Peta Rencana (Roadmap) Riset Enterprise Resource Planning (ERP) Dengan Fokus Riset Pada Usaha Kecil Dan Menengah (UKM) Di Indonesia. Journal of Information Systems, 140-145.

Stokes, D., \& Wilson, N. (2010). Small Business Management and Entrepreneurship. Hampshire: Cengage Learning EMEA. 